\title{
Measurements of particle masses of inorganic salt particles for calibration of cloud condensation nuclei counters
}

\author{
M. Kuwata ${ }^{1, *}$ and Y. Kondo ${ }^{1}$ \\ ${ }^{1}$ Research Center for Advanced Science and Technology, the University of Tokyo, Tokyo, Japan \\ * currently at: School of Engineering and Applied Sciences, Harvard University, Cambridge, MA, USA
}

Received: 7 January 2009 - Published in Atmos. Chem. Phys. Discuss.: 24 February 2009

Revised: 27 July 2009 - Accepted: 1 August 2009 - Published: 19 August 2009

\begin{abstract}
We measured the mobility equivalent critical dry diameter for cloud condensation nuclei $(\mathrm{CCN})$ activation $\left(d_{c \_m e}\right)$ and the particle mass of size-selected $\left(\mathrm{NH}_{4}\right)_{2} \mathrm{SO}_{4}$ and $\mathrm{NaCl}$ particles to calibrate a CCN counter (CCNC) precisely. The CCNC was operated downstream of a differential mobility analyzer (DMA) for the measurement of $d_{c \_m e}$. The particle mass was measured using an aerosol particle mass analyzer (APM) operated downstream of the DMA. The measurement of particle mass was conducted for 50-150-nm particles. Effective densities $\left(\rho_{\text {eff }}\right)$ of $\left(\mathrm{NH}_{4}\right)_{2} \mathrm{SO}_{4}$ particles were $1.67-1.75 \mathrm{~g} \mathrm{~cm}^{-3}$, which correspond to dynamic shape factors $(\chi)$ of 1.01-1.04. This shows that $\left(\mathrm{NH}_{4}\right)_{2} \mathrm{SO}_{4}$ particles are not completely spherical. In the case of $\mathrm{NaCl}$ particles, $\rho_{\text {eff }}$ was $1.75-1.99 \mathrm{~g} \mathrm{~cm}^{-3}$ and $\chi$ was $1.05-1.14$, demonstrating that the particle shape was non-spherical. Using these experimental data, the volume equivalent critical dry diameter $\left(d_{c_{-} v e}\right)$ was calculated, and it was used as an input parameter for calculations of critical supersaturation $(S)$. Several thermodynamics models were used for the calculation of water activity. When the Pitzer model was employed for the calculations, the critical $S$ calculated for $\left(\mathrm{NH}_{4}\right)_{2} \mathrm{SO}_{4}$ and $\mathrm{NaCl}$ agreed to well within the uncertainty of $2 \%$ (relative). This result demonstrates that the use of the Pitzer model for the calibration of CCNCs gives the most accurate value of $S$.
\end{abstract}

\section{Introduction}

The number concentration of cloud condensation nuclei (CCN) is an important parameter for cloud microphysics. The number concentration and size distribution of cloud droplets are affected by changes in the $\mathrm{CCN}$ number concentration. Consequently, CCN number concentration is indi-

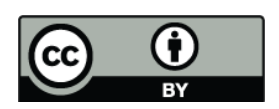

Correspondence to: M. Kuwata (kuwata@atmos.rcast.u-tokyo.ac.jp) rectly related to radiative forcing and the hydrological cycle. Thus, it is important to measure the CCN number concentration and CCN activity of atmospheric particles precisely (Twomey, 1974; Lohmann and Feichter, 2005, and references therein).

$\mathrm{CCN}$ number concentration is measured using a $\mathrm{CCN}$ counter (CCNC). Several types of CCNCs have been developed (McMurry, 2000; Nenes et al., 2001; Roberts and Nenes, 2005). In most CCNCs, supersaturated conditions are produced by creating a temperature difference on wetted walls. CCN-active particles grow to large droplets in the artificial supersaturated environment. The number of droplets is then counted using an optical particle counter (OPC) (e.g., Stratmann et al., 2004; Roberts and Nenes, 2005) or a charge coupled device (CCD) camera (Otto et al., 2002). The most important parameter in $\mathrm{CCN}$ measurement is the precise value of the supersaturation $(S)$ inside the instrument, which ensures compatibility with other studies (Seinfeld and Pandis, 2006).

$S$ inside a CCNC can be calculated theoretically (e.g., Nenes et al., 2001; Stratmann et al., 2004; Roberts and Nenes, 2005). These theoretical studies are indispensable for developing CCNCs. However, theoretical results are not sufficient for practical observations and experiments as the ideal instrument does not exist and instrumental conditions can change with time. Therefore, routine calibrations are required for the operation of CCNCs (e.g., Rose et al., 2008). Unfortunately, there are no instruments that can measure $S$ directly; thus, we have to choose an alternative method for calibration. In most CCN studies, the critical dry diameters (the threshold diameters for $\mathrm{CCN}$ activation, $d_{c}$ ) of laboratory-generated particles are measured using a CCNC connected to a differential mobility analyzer (DMA) in tandem to calibrate the instruments. Then, the critical $S$ values corresponding to the observed $d_{c}$ values are calculated using Köhler theory. $\left(\mathrm{NH}_{4}\right)_{2} \mathrm{SO}_{4}$ is the most frequently used compound for calibration (e.g., Kumar et al., 2003; VanReken et

Published by Copernicus Publications on behalf of the European Geosciences Union. 
al., 2005), and some studies also use $\mathrm{NaCl}$ particles (Rissman et al., 2007; Shilling et al., 2007; Rose et al., 2008). However, the critical $S$ of $\left(\mathrm{NH}_{4}\right)_{2} \mathrm{SO}_{4}$ particles is strongly dependent on thermodynamics models (Kreidenweis et al., 2005), and the magnitude of the variation is large enough to change the interpretation of the observation results (e.g., Mochida et al., 2006). In the case of $\mathrm{NaCl}$, the differences between thermodynamics models are not as significant as those of $\left(\mathrm{NH}_{4}\right)_{2} \mathrm{SO}_{4}$, and there is an excellent thermodynamics model that is based on the various experimental data (Archer, 1992). However, it is difficult to estimate the critical $S$ of a DMA-selected $\mathrm{NaCl}$ particle because of its non-spherical shape (Kelly and McMurry, 1992; Zelenyuk et al., 2006a). In previous studies, $S$ values calculated using the two different compounds did not always agree, and the magnitude of the difference was up to $10 \%$ (relative) (e.g., Shilling et al., 2007). These discrepancies were possibly caused by the uncertainties described above. Rose et al. (2008) have suggested that the shape factor of $\mathrm{NaCl}$ particles varies between 1.0 and 1.08 based on measurements of the $\mathrm{CCN}$ activity of $\mathrm{NaCl}$ particles. We have measured this quantity more accurately using a more direct method.

In this study, we measured the masses of $\left(\mathrm{NH}_{4}\right)_{2} \mathrm{SO}_{4}$ and $\mathrm{NaCl}$ particles generated for the calibration of a CCNC using an aerosol particle mass analyzer (APM). The APM can select particles according to their mass by virtue of the balance between electrostatic and centrifugal forces (Ehara et al., 1996). Thus, the combination of a DMA and an APM (DMA-APM system) enables us to measure the mass of DMA-selected particles, and we can obtain parameters related to particle morphology such as $\chi$ (e.g., Park et al., 2004). Then, $S$ values inside the CCNC were calculated using the measured $d_{c}$, particle mass, and several thermodynamics models. The calculated $S$ values are compared to investigate the consistency of the experimental results of $\left(\mathrm{NH}_{4}\right)_{2} \mathrm{SO}_{4}$ and $\mathrm{NaCl}$ particles.

\section{Theoretical background}

\subsection{The relationship of $d_{m e}$ and $d_{v e}$}

In this section, we summarize the relationship between mobility diameter $\left(d_{m e}\right)$ and volume equivalent diameter $\left(d_{v e}\right)$, because the conversion of $d_{m e}$ to $d_{v e}$ is needed to prepare an input parameter for calculations based on Köhler theory (Sect. 2.2). For spherical particles, $d_{m e}$ is equal to $d_{v e}$. However, particles are not always spherical. Using the effective density ( $\left.\rho_{\text {eff }}\right), d_{m e}$ is related with $d_{v e}$ by the following equation (DeCarlo et al., 2004):

$m_{p}=\frac{\pi}{6} \rho_{m} d_{v e}^{3}=\frac{\pi}{6} \rho_{\mathrm{eff}} d_{m e}^{3}$

or

$d_{v e}=\sqrt[3]{\frac{\rho_{\mathrm{eff}}}{\rho_{m}}} d_{m e}$ where $m_{p}$ is particle mass, and $\rho_{m}$ is the material density. In the DMA-APM system, $d_{m e}$ is known as it is prescribed by the DMA, and $m_{p}$ can be measured using the APM. Thus, if we apply this experimental system to particles composed of single compounds, we can obtain the conversion factor $\left(\sqrt[3]{\frac{\rho_{\text {eff }}}{\rho_{m}}}\right)$ easily, as $\rho_{m}$ is a known parameter.

$d_{v e}$ and $d_{m e}$ can also be related by $\chi$, which is defined as the ratio of the drag force acting on spherical particles with diameters of $d_{v e}$ and $d_{m e}$. Under the equilibrium sphere approximation (ESA) (Dahneke, 1973), $\chi$ is defined by the following equation (Kasper, 1982):

$\chi=\frac{Z_{p}\left(d_{v e}\right)}{Z_{p}\left(d_{m e}\right)}=\frac{C_{c}\left(d_{v e}\right)}{d_{v e}} \frac{d_{m e}}{C_{c}\left(d_{m e}\right)}$

where $Z_{p}$ is the electrical mobility, and the slip correction factor $\left(C_{c}\right)$ can be calculated from the following equation (Allen and Raabe, 1985):

$C_{c}=1+\frac{2 \lambda}{d_{p}}\left(1.142+0.558 \exp \left(\frac{\frac{-0.009}{2 \lambda}}{d_{p}}\right)\right)$

where $\lambda$ is mean free path of air. Although ESA is a good approximation for slightly non-spherical particles and it is useful to calculate $\chi$ from experimental results, it is not always appropriate to use ESA for studies of $\chi$ in the transition regime $\left(\chi_{t}\right)$, especially for particles that are highly non-spherical (Dahneke, 1973). For this purpose, the adjusted sphere approximation (ASA) was introduced (Dahneke, 1973). Using ASA, $\chi_{t}$ can be written as follows (DeCarlo et al., 2004):

$\chi_{t}=\chi_{c} \frac{C_{c}\left(d_{v e}\right)}{C_{c}\left(\frac{\chi_{f}}{\chi_{c}} d_{v e}\right)}$

where, $\chi_{f}$ and $\chi_{c}$ denote $\chi$ in the free molecular regime and continuous regime, respectively.

\subsection{Köhler theory}

The water activity of an aqueous solution $\left(a_{w}\right)$ is equal to the saturation ratio of water vapor (Robinson and Stokes, 2002)

$\frac{p_{w}}{p_{w}^{0}}=a_{w}$

where $p_{w}$ is the vapor pressure of water and $p_{w}^{0}$ is the saturation vapor pressure of water. For an aqueous solution in gas-liquid equilibrium, $p_{w}$ is equal to the equilibrium water vapor pressure of a solution having a flat surface. In the case of particles, the equilibrium vapor pressure of the solution ( $\left.p_{w \_ \text {aerosol }}\right)$ is affected by the curvature of the droplet (Kelvin effect). The magnitude of this effect is described as follows (Seinfeld and Pandis, 2006)

$\frac{p_{w \_ \text {aerosol }}}{p_{w}}=\exp \left(\frac{4 \sigma M_{w}}{R T \rho_{w} D_{p}}\right)$ 
where $\sigma$ is surface tension, $M_{w}$ is the molecular weight of water, $R$ is the gas constant, $T$ is temperature, $\rho_{w}$ is the density of water, and $D_{p}$ is the droplet diameter. Substituting Eq. (7) into (6), we get

$s=\frac{p_{w \_ \text {aerosol }}}{p_{w}^{0}}=a_{w} \exp \left(\frac{4 \sigma M_{w}}{R T \rho_{w} D_{p}}\right)$

where $s$ is the saturation ratio of water vapor. Thus, $a_{w}$ is needed to calculate $s$. There are several expressions for the $a_{w}$ of solution. One of the most commonly used expressions is the equation defining the molal osmotic coefficient $(\phi)$ (Robinson and Stokes, 2002);

$\ln a_{w}=-v m M_{w} \varphi$

where $v$ is the stoichiometric number of solute ions and molecules, and $m$ (molality) is defined as follows:

$m=\frac{m_{s}}{M_{s} m_{w}}$.

In Eq. (10), $m_{s}$ is the mass of solute, $M_{s}$ is molecular weight of solute, and $m_{w}$ is the mass of water in aqueous solution. The van't Hoff factor $(i)$ is also frequently used to express $a_{w}$. The value $i$ is defined as follows:

$a_{w}=\frac{n_{w}}{n_{w}+i n_{s}}$

where $n_{w}$ and $n_{i}$ are the numbers of moles of water (solvent) and solute, respectively (Pruppacher and Klett, 1997). As an example of another expression, Tang and Munkelwitz (1994) and Tang (1996) expressed $a_{w}$ as a polynomial equation with respect to the concentration of the solution (weight percent). Thermodynamics models employed for the present study are summarized in Appendix B. Among the models summarized in Appendix B, we regard that of Archer (1992) as the most reliable, as it is based on a number of experimental results, including the concentration range that is important for $\mathrm{CCN}$ activation (Clegg, 2007). We next derive Köhler theory using $\phi$. Similar equations can easily be obtained for other expressions of $a_{w}$.

Using Eqs. (8), (9), and (10), we get

$$
\ln s=\frac{4 \sigma M_{w}}{R T \rho_{w} D_{p}}-v \varphi \frac{M_{w} m_{s}}{M_{s} m_{w}} .
$$

In Eq. (12), we need to know $m_{s}$ for the calculation of $s$. It is equal to $m_{p}$ when the particle is composed of a single component. Then, Eq. (12) can be rewritten using $d_{v e}$ (Eq. 1),

$$
\ln s=\frac{4 \sigma M_{w}}{R T \rho_{w} D_{p}}-v \varphi \frac{M_{w} \rho_{m} d_{v e}^{3}}{M_{s} \rho_{w}\left(D_{p}^{3}-d_{v e}^{3}\right)}
$$

When we calculate $s$ of a single particle as a function of $D_{p}$, it has a maximum value. $S$ corresponding to this value is called the critical $S$. If the particle is subjected to an $S$ greater than the critical $S$, the particle can grow into a cloud droplet.
Table 1. $M_{s}, \rho_{m}$, and $v$ of $\left(\mathrm{NH}_{4}\right)_{2} \mathrm{SO}_{4}$ and $\mathrm{NaCl}$.

\begin{tabular}{lrrr}
\hline & $M_{s}\left(\mathrm{~g} \mathrm{~mol}^{-1}\right)$ & $\rho_{m}\left(\mathrm{~g} \mathrm{~cm}^{-3}\right)$ & $v$ \\
\hline$\left(\mathrm{NH}_{4}\right)_{2} \mathrm{SO}_{4}$ & 132.14 & 1.77 & 3 \\
$\mathrm{NaCl}$ & 58.44 & 2.16 & 2
\end{tabular}

\section{Experiment}

\subsection{Particle generation and classification}

The experimental setup used in this study is shown in Fig. 1. Aqueous solutions ( $\sim 0.1$ weight $\%)$ of $\left(\mathrm{NH}_{4}\right)_{2} \mathrm{SO}_{4}$ and $\mathrm{NaCl}$ were prepared and introduced into an atomizer (TSI model 3076). Chemical properties of these compounds are summarized in Table 1. Synthetic compressed air supplied from a gas cylinder was used for this atomizer. Particles were dried by passing them through two diffusion dryers (TSI model 3062) connected in tandem. Silica gel used for the diffusion dryers was regenerated before each run. Then, particles were charged with a ${ }^{241} \mathrm{Am}$ neutralizer, and their size was selected by a DMA (TSI model 3081). The sheath and sample flow rates of the DMA were set at $3.0 \mathrm{lpm}$ and $0.3 \mathrm{lpm}$, respectively. The size selection of the DMA was checked by measuring size distributions of the polystyrene latex (PSL) particles listed in Table 2. The peak diameters of the sizedistributions agreed with the diameters of the PSL to within the errors given by the manufacturers. In this paper, we report diameters by the set values of the DMA. The random error in diameter estimated from the PSL measurements was less than $0.5 \%$.

\subsection{CCN measurement}

The CCN measurement part of Fig. 1 was used to determine the mobility equivalent critical dry diameter $\left(d_{c \_m e}\right)$. A CCNC (Droplet Measurement Technologies, DMT) (Roberts and Nenes, 2005) was used to measure CCN number concentration, and a condensation particle counter (CPC: TSI model 3022) was used for $\mathrm{CN}$ measurement. The sample flow from the DMA was mixed with dry compressed particlefree air $(0.5 \mathrm{lpm})$ to keep the sample flow rate of the DMA at $0.3 \mathrm{lpm}$. Dilution air was produced from air in the laboratory using a pure air generator (PAG 003, ECO Physics) and a high-efficiency particulate air (HEPA) filter. The flow rate of the dilution air was controlled by a mass flow controller. The sample flow and the sheath flow rates of the CCNC were set to $0.045 \mathrm{lpm}$ and $0.455 \mathrm{lpm}$, respectively. Two temperature gradient $(\Delta T)$ conditions of the thermal gradient chamber inside the CCNC were used as shown in Table 3 so that the measurement was performed at two $S$ values. Solenoid pumps used for water circulation in the CCNC were replaced by external peristaltic pumps for flow stabilization. The air 
Table 2. List of PSL particles used for the calibration of the DMA and APM.

\begin{tabular}{|c|c|c|c|}
\hline $\begin{array}{c}d_{p} \\
(\mathrm{~nm})\end{array}$ & $\begin{array}{c}\rho_{m} \\
\left(\mathrm{~g} \mathrm{~cm}^{-3}\right)^{\mathrm{a}}\end{array}$ & $\begin{array}{l}\text { Mass range } \\
(\mathrm{fg})^{\mathrm{b}}\end{array}$ & $\begin{array}{l}\text { Manufacturer } \\
\text { (product name) }\end{array}$ \\
\hline $48 \pm 1$ & 1.061 & $0.058-0.065$ & $\begin{array}{l}\text { JSR corporation } \\
\text { (STADEX SC-0050-D) }\end{array}$ \\
\hline $61 \pm 1$ & 1.065 & $0.12-0.13$ & $\begin{array}{l}\text { JSR corporation } \\
\text { (STADEX SC-0060-D) }\end{array}$ \\
\hline $76 \pm 2$ & 1.057 & $0.22-0.26$ & $\begin{array}{l}\text { JSR corporation } \\
\text { (STADEX SC-0075-D) }\end{array}$ \\
\hline $102 \pm 3$ & 1.05 & $0.53-0.64$ & $\begin{array}{l}\text { Duke Scientific Corporation } \\
\text { (NANOSPHERE SIZE STANDARDS) }\end{array}$ \\
\hline $152 \pm 5$ & 1.05 & $1.7-2.1$ & $\begin{array}{l}\text { Duke Scientific Corporation } \\
\text { (NANOSPHERE SIZE STANDARDS) }\end{array}$ \\
\hline
\end{tabular}

a Density given by the manufacturers as a reference.

$\mathrm{b}$ Particle mass was calculated using the diameter range and density.

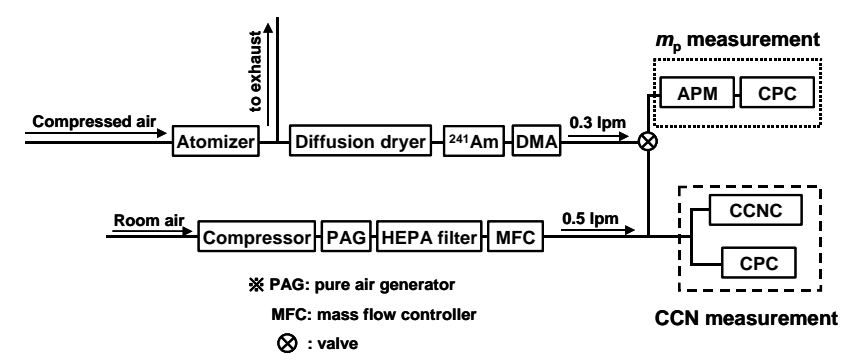

Fig. 1. Experimental setup used in this study.

circulation system for the OPC drying system was plugged to stabilize the airflow in the chamber. The reproducibility of $d_{c \_m e}$ measurement was tested using $\left(\mathrm{NH}_{4}\right)_{2} \mathrm{SO}_{4}$ particles. The random errors associated with $d_{c \_m e}$ measurement were 0.1 and $0.3 \mathrm{~nm}$ for $\Delta T 1$ and $\Delta T 2$, respectively. The influence of this error on the critical $S$ was calculated to be negligibly small (less than $0.001 \%$, absolute). Although, we employed the CCNC manufactured by DMT, the present result is applicable for other types of CCNCs, as they are calibrated similarly (e.g., Snider et al., 2006; Frank et al., 2007).

\subsection{DMA-APM system}

An APM (APM 302, KANOMAX JAPAN, Inc.) was employed to measure $m_{p}$ of particles prescribed by the DMA. The $m_{p}$ selected by the APM is described as follows (Ehara et al., 1996),

$m_{p}=\frac{n e V_{\mathrm{APM}}}{w^{2} r^{2} \ln \left(r_{2} / r_{1}\right)}$

where $n$ is the number of charges, $e$ is the elementary charge, $V_{\mathrm{APM}}$ is the voltage applied to the APM, $\omega$ is the rotation speed, and $r, r_{1}$, and $r_{2}$ are the center, inner, and outer radii of the APM operating space, respectively. Particle number concentration downstream of the APM was measured by a CPC

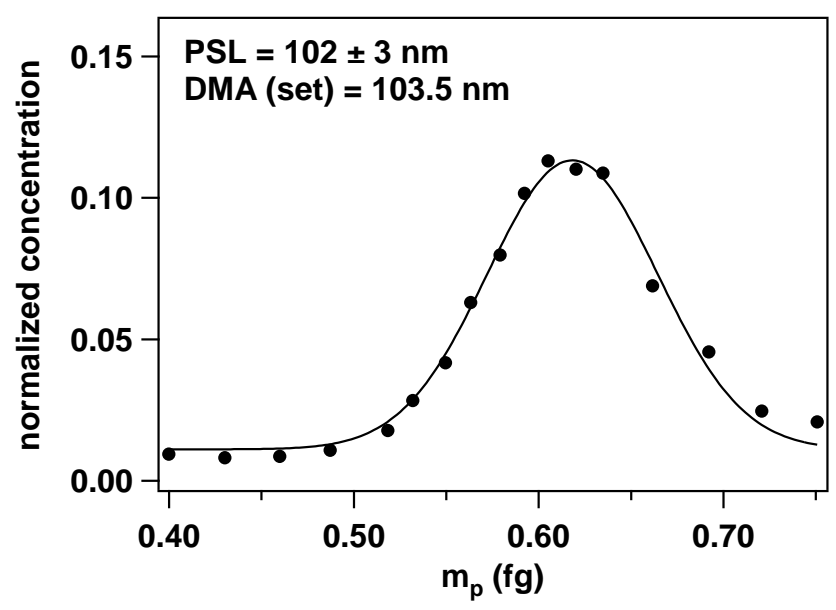

Fig. 2. Example mass distribution of PSL particles prescribed by the DMA.

(TSI model 3022). To calibrate $m_{p}$ and $\rho_{\text {eff }}$ measurement by the DMA-APM system, the masses of DMA-selected PSL particles were measured. Figure 2 shows an example of a mass distribution of DMA-selected PSL particles. The peak of the distribution, which corresponds to $m_{p}$, was obtained by fitting the distribution by a Gaussian function. The measured values of $m_{p}$ agreed with the calculated values within the errors associated with PSL particles (Table 2). Density calculated using Eqs. (14) and (1) (in this case, we can assume $d_{v e}=d_{m e}$, as PSL particles have spherical shape) agreed with the values given by the manufacturers to within $5 \%$, and this difference was corrected for inorganic salt particles. Linear interpolation was employed for the correction, as the difference was size-dependent. Relative contributions of the DMA and APM to the difference were not quantified. The random error associated with the $\rho_{\text {eff }}$ measurement by the DMA-APM system was $1 \%$, estimated from PSL measurements. 
Table 3. Temperatures of the thermal gradient chamber in the CCNC. $T 1, T 2$, and $T 3$ correspond to the temperatures at the top, middle, and the bottom of the chamber, respectively.

\begin{tabular}{ccccc}
\hline & $T$ inlet $(\mathrm{K})$ & $T 1(\mathrm{~K})$ & $T 2(\mathrm{~K})$ & $T 3(\mathrm{~K})$ \\
\hline$\Delta T 1$ & $301.3 \pm 0.1$ & $300.48 \pm 0.02$ & $301.86 \pm 0.02$ & $303.16 \pm 0.02$ \\
$\Delta T 2$ & $301.9 \pm 0.1$ & $301.10 \pm 0.02$ & $303.18 \pm 0.02$ & $305.08 \pm 0.02$ \\
\hline
\end{tabular}

The measurement of $\rho_{\text {eff }}$ was performed four times. RUN1 and RUN2 were performed prior to $\mathrm{CCN}$ measurement. RUN3 was performed soon after (within $5 \mathrm{~h}$ ) the CCN measurement at $\Delta T 1$, and we concentrated on the size range that is important for CCN activation under these conditions. Likewise, RUN4 was performed soon after the CCN measurement at $\Delta T 2$.

\section{Results and discussion}

\section{1 $d_{c \_m e}$ of inorganic salt particles}

Figure 3 shows experimental results for the $\mathrm{CCN}$ measurement of $\left(\mathrm{NH}_{4}\right)_{2} \mathrm{SO}_{4}$ and $\mathrm{NaCl}$ particles. CCN/CN ratios monotonically increase with increasing diameter and approach unity. The CCN/CN ratios are fitted by a sigmoid function (Eq. 15):

$$
\frac{\mathrm{CCN}}{\mathrm{CN}}=a+\frac{b}{1+\exp \left(\frac{d_{c \_m e}-d_{m e}}{c}\right)}
$$

where $a, b$, and $c$ are constants determined by the fitting. $d_{c_{-} m e}$ values were $115.2 \mathrm{~nm}(\Delta T 1)$ and $75.3 \mathrm{~nm}(\Delta T 2)$ for $\left(\mathrm{NH}_{4}\right)_{2} \mathrm{SO}_{4}$ and $94.7 \mathrm{~nm}(\Delta T 1)$ and $63.2 \mathrm{~nm}(\Delta T 2)$ for $\mathrm{NaCl}$, respectively.

\section{2 $\rho_{\text {eff }} \chi$ and $d_{v e}$ of inorganic salt particles}

Figure 4 shows an example mass distribution of DMAselected $\mathrm{NaCl}$ particles measured using the APM and CPC. As in the case of PSL, these distributions were fitted by Gaussian functions to obtain the peak of the distribution, and then we obtained the particle mass. $\rho_{\text {eff }}, d_{v e}$ and $\chi$ were calculated from the experimental results. The calculated values are summarized in Fig. 5. ESA was used to calculate $\chi$ in all cases, as $\chi_{f}$ and $\chi_{c}$ are not available. In the case of $\left(\mathrm{NH}_{4}\right)_{2} \mathrm{SO}_{4}$, the measured values of $\rho_{\text {eff }}\left(1.67 \sim 1.75 \mathrm{~g} \mathrm{~cm}^{-3}\right)$ were slightly smaller than the bulk density $\left(1.77 \mathrm{~g} \mathrm{~cm}^{-3}\right.$ ) (Fig. 5a), and $\chi$ was slightly larger than unity $(1.01 \sim 1.04)$ (Fig. 5b). These values are similar to those obtained by Zelenyuk et al. (2006a), who showed that the $\chi$ of $\left(\mathrm{NH}_{4}\right)_{2} \mathrm{SO}_{4}$ is $1.03 \pm 0.01$ at $160 \mathrm{~nm}$ using a DMA and a single-particle laser ablation time-of-flight mass spectrometer (SPLAT). Biskos et al. (2006a) estimated a $\chi$ (a)
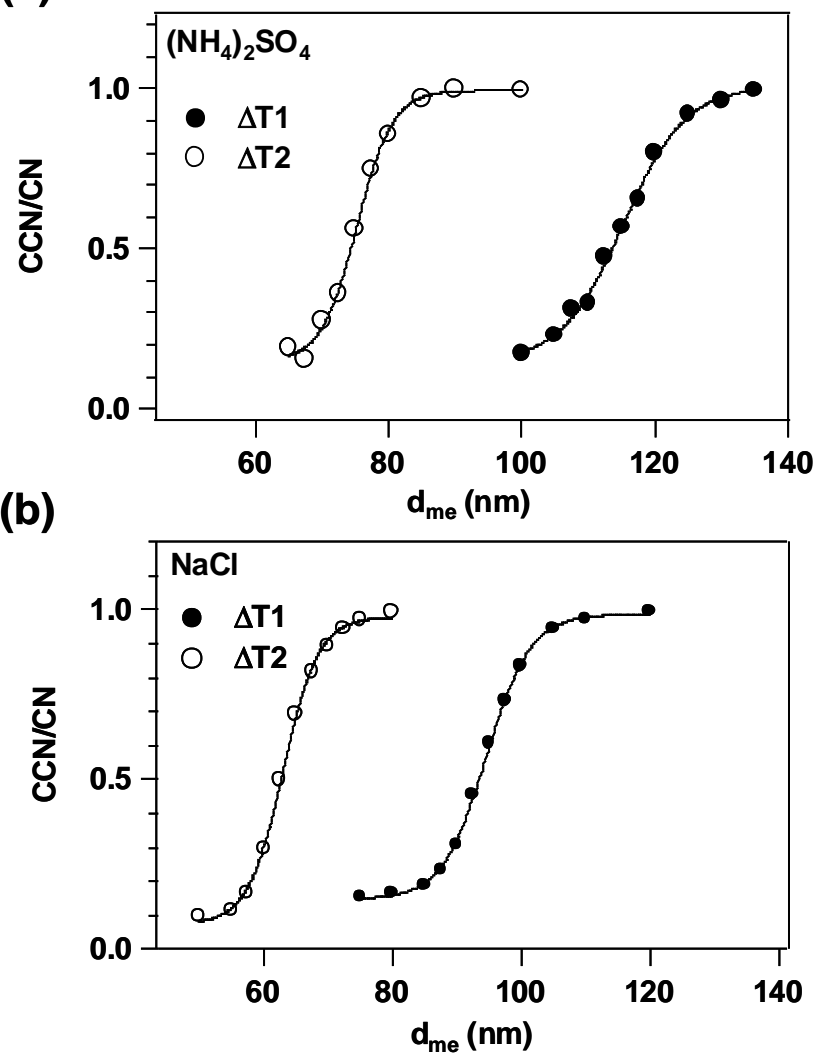

Fig. 3. $\mathrm{CCN}$ activation curves of $\left(\mathrm{NH}_{4}\right)_{2} \mathrm{SO}_{4}$ and $\mathrm{NaCl}$ particles under two experimental conditions $(\Delta T 1$ and $\Delta T 2)$.

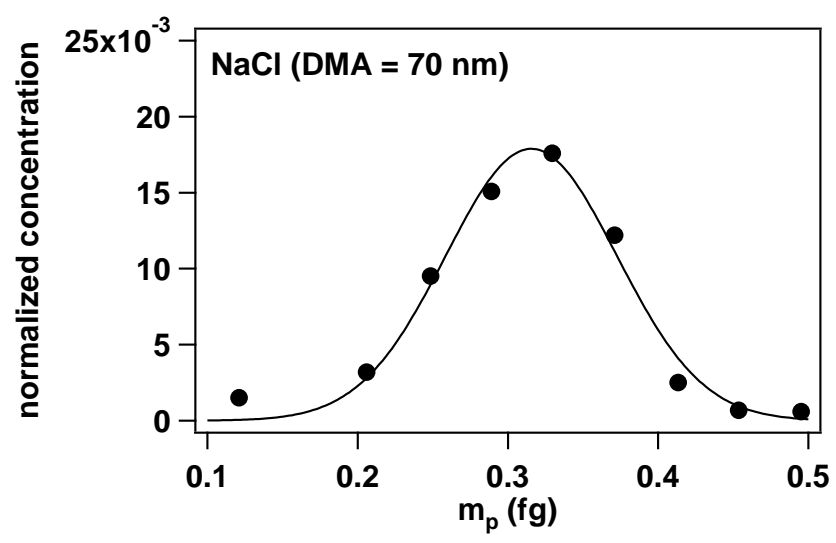

Fig. 4. Example mass distribution of $\mathrm{NaCl}$ particles prescribed by the DMA. The solid line is the fitting result of the experimental data to a Gaussian function.

for 6-60-nm $\left(\mathrm{NH}_{4}\right)_{2} \mathrm{SO}_{4}$ particles of 1.02 to explain the discrepancy between theoretical calculations and experimental results of the hygroscopicity measurement. These results indicate that $\left(\mathrm{NH}_{4}\right)_{2} \mathrm{SO}_{4}$ particles do not have a completely spherical shape, as observed by electron microscope (Dick et al., 1998; Zelenyuk et al., 2006a). Comparing the results 
(a)

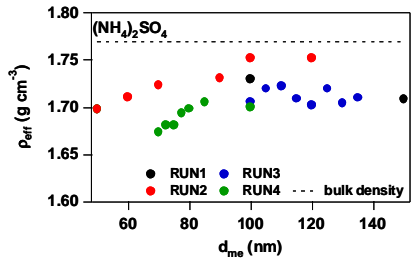

(b)

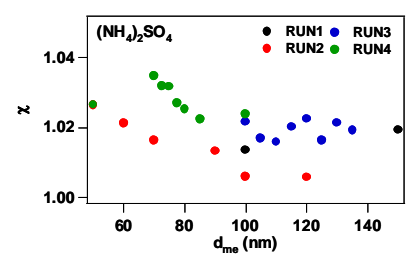

(c)

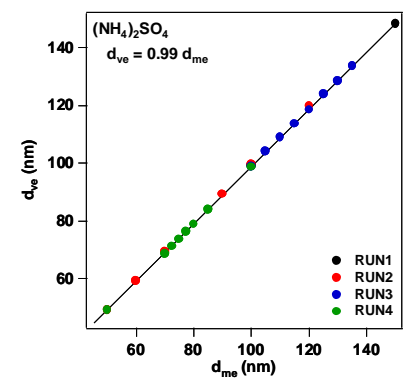

(d)

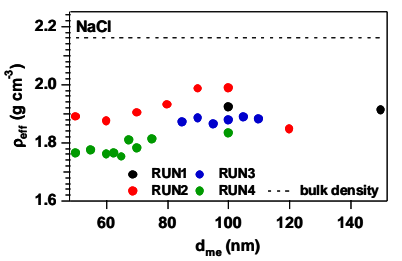

(e)

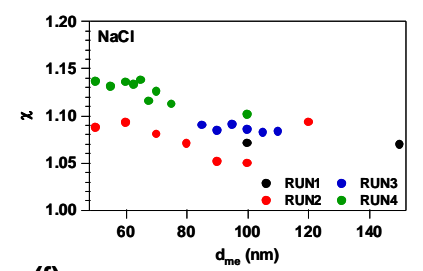

(f)

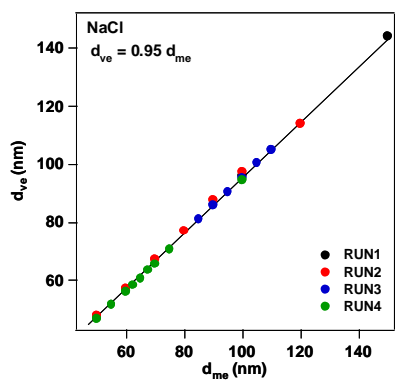

Fig. 5. $\rho_{\text {eff }}, \chi$, and $d_{v e}$ of $\left(\mathrm{NH}_{4}\right)_{2} \mathrm{SO}_{4}$ and $\mathrm{NaCl}$ particles measured using the DMA-APM system. (a) $\rho_{\text {eff }}$ of $\left(\mathrm{NH}_{4}\right)_{2} \mathrm{SO}_{4}$, (b) $\chi$ of $\left(\mathrm{NH}_{4}\right)_{2} \mathrm{SO}_{4}$, (c) $d_{v e}$ of $\left(\mathrm{NH}_{4}\right)_{2} \mathrm{SO}_{4}$, (d) $\rho_{\text {eff }}$ of $\mathrm{NaCl},(\mathbf{e}) \chi$ of $\mathrm{NaCl}$, and (f) $d_{v e}$ of $\mathrm{NaCl}$ particles.

of RUN1 $\sim$ RUN4, systematic differences are observed. $\rho_{\text {eff }}$ was the highest in RUN2 and lowest in RUN4. These differences are greater than the uncertainty of the $\rho_{\text {eff }}$ measurement (1\%). Zelenyuk et al. (2006b) reported that rapid drying causes particles to have a more irregular shape. Thus, we suspect that these differences found are possibly caused by different conditions of the silica gel in the diffusion dryer in each run. Figure $5 \mathrm{c}$ shows the relationship between $d_{m e}$ and $d_{v e}$ of $\left(\mathrm{NH}_{4}\right)_{2} \mathrm{SO}_{4}$ particles. As can be easily expected from the values of $\chi$, the slope is almost equal to unity (0.99). Considering that the error in the diameter of PSL particles is typically about $3 \%$ (Table 2), this result shows that $\left(\mathrm{NH}_{4}\right)_{2} \mathrm{SO}_{4}$ particles can be treated approximately as spherical in most cases.

Figure $5 \mathrm{~d}$ and e show $\rho_{\text {eff }}$ and $\chi$ of $\mathrm{NaCl}$ particles, respectively. $\rho_{\text {eff }}\left(1.75 \sim 1.99 \mathrm{~g} \mathrm{~cm}^{-3}\right)$ was smaller than the bulk density $\left(2.16 \mathrm{~g} \mathrm{~cm}^{-3}\right)$, and $\chi$ was significantly larger than unity (1.05 1.14). Kelly and McMurry (1992) used a DMA and an impactor to measure $\rho_{\text {eff }}$ of $\mathrm{NaCl}$ particles $\left(d_{m e}=111 \mathrm{~nm}\right)$. They reported that $\rho_{\text {eff }}$ was equal to $1.86 \mathrm{~g} \mathrm{~cm}^{-3}(\chi=1.08)$. Zelenyuk et al. (2006a) measured $\rho_{\text {eff }}$ of $\mathrm{NaCl}\left(d_{m e}=160 \sim 850 \mathrm{~nm}\right)$ using a DMA and a SPLAT. They showed that $\rho_{\text {eff }} \sim 1.95 \mathrm{~g} \mathrm{~cm}^{-3}(\chi \sim 1.06)$ at $160 \mathrm{~nm}$.

Table 4. Values of $d_{c_{-} v e}$ used for the calculation of $S$.

\begin{tabular}{lllll}
\hline & \multicolumn{3}{c}{$\Delta T 1$} & \multicolumn{2}{c}{$\Delta T 2$} \\
\hline & $\left(\mathrm{NH}_{4}\right)_{2} \mathrm{SO}_{4}$ & $\mathrm{NaCl}$ & $\left(\mathrm{NH}_{4}\right)_{2} \mathrm{SO}_{4}$ & $\mathrm{NaCl}$ \\
$d_{c_{-} v e}(\mathrm{~nm})$ & 113.9 & 90.3 & 74.0 & 59.2 \\
\hline
\end{tabular}

Mikhailov et al. (2004) estimated that $\chi$ is equal to 1.06 $(99 \mathrm{~nm})$ and $1.07(201 \mathrm{~nm})$ from hygroscopicity measurements. These values show that the shape of $\mathrm{NaCl}$ particles is significantly different from spherical. Our results shown in Fig. 5 are similar to these other studies except for RUN4. In that case, $\chi$ was systematically higher than the other cases $(1.10 \sim 1.14)$. This value is higher than the $\chi$ for a cubic shape in the continuous regime (1.08) (Hinds, 1999). Biskos et al. (2006b) showed that $\chi$ calculated by ASA for a cubic shape is needed to explain hygroscopic growth of $d_{m e}=6-$ $60-\mathrm{nm} \mathrm{NaCl}$ particles. $\chi$ is about 1.2 for $d_{m e}=50-100 \mathrm{~nm}$ when we employ ASA to calculate the $\chi$ of cubic particles. Thus, we regard the results of RUN4 as quite reasonable, considering that the shape of $\mathrm{NaCl}$ particles is cubic with rounded edges (Zelenyuk et al., 2006a). Figure $5 \mathrm{f}$ shows the relationship between $d_{m e}$ and $d_{v e}$ of $\mathrm{NaCl}$ particles. $d_{v e}$ is smaller than $d_{m e}$ by $3-7 \%$, and the value of the slope is 0.95 . This shows that morphology should be considered when using $\mathrm{NaCl}$ particles for calibration experiments (Rose et al., 2008). The measurements of $\chi$ and $\rho_{\text {eff }}$ without employing thermodynamics models are limited to the size range of $<150 \mathrm{~nm}$ (e.g., Kelly and McMurry, 1992). Our data are also useful for the investigation of the hygroscopic growth of particles in this size range.

\subsection{Calculation of $S$}

In this section, we estimate $S$ inside the CCNC using experimental results shown in Sects. 4.1 and 4.2. In order to calculate volume equivalent critical dry diameter $\left(d_{c \_v e}\right), d_{c \_m e}$ and $\rho_{\text {eff }}$ at $d_{c \_m e}$ are required (Eq. 1). The $d_{c \_m e}$ shown in Sect. 4.1 was used, and $\rho_{\text {eff }}$ at $d_{c \_m e}$ was calculated by interpolating the corresponding experimental result of the DMAAPM system measurement (RUN3 and RUN4 for $\Delta T 1$ and $\Delta T 2$, respectively). The values of $d_{c_{-} v e}$ used for the calculation are summarized in Table 4 . The calculation was performed using the temperatures at $T 2$ (Table 3).

Table 5 shows the calculated results. As discussed in Sect. 2.2, we regard the model of Archer (1992) as the most reliable. Using this model, $S$ values were calculated to be $0.117 \%$ and $0.220 \%$ for $\Delta T 1$ and $\Delta T 2$, respectively. Thus, we regard these values as the most probable values of $S$ in the $\mathrm{CCN}$ chamber.

In the case of $\mathrm{NaCl}$ particles at $\Delta T 1$, the value calculated using the approach of Tang (1996) was the lowest, and a higher $S$ value was obtained with the approach of 
Table 5. $S$ values calculated using several thermodynamics models. See text for the input parameters and descriptions of the models. "N/A" denotes that the thermodynamic data is not available.

\begin{tabular}{lllll}
\hline & \multicolumn{2}{c}{$\Delta T 1$} & \multicolumn{2}{c}{$\Delta T 2$} \\
\hline Model & $\left(\mathrm{NH}_{4}\right)_{2} \mathrm{SO}_{4}(\%)$ & $\mathrm{NaCl}(\%)$ & $\left(\mathrm{NH}_{4}\right)_{2} \mathrm{SO}_{4}(\%)$ & $\mathrm{NaCl}(\%)$ \\
\hline Ideal solution approximation & 0.110 & 0.115 & 0.207 & 0.214 \\
Archer (1992) & $\mathrm{N} / \mathrm{A}$ & 0.117 & $\mathrm{~N} / \mathrm{A}$ & 0.220 \\
Clegg et al. (1996) & 0.117 & $\mathrm{~N} / \mathrm{A}$ & 0.225 & N/A \\
Pitzer and Mayorga (1973) & 0.117 & 0.117 & 0.225 & 0.220 \\
Young and Warren (1992) & 0.118 & N/A & 0.228 & N/A \\
Tang and Munkelwitz (1994) & 0.135 & N/A & 0.256 & N/A \\
Tang (1996) & N/A & 0.113 & N/A & 0.211 \\
Kreidenweis et al. (2005) & 0.139 & 0.115 & 0.262 & 0.215 \\
\hline
\end{tabular}

Kreidenweis et al. (2005) and the ideal solution approximation. The values calculated using the Pitzer models (Pitzer and Mayorga, 1973; Archer et al., 1992) are the same. For $\left(\mathrm{NH}_{4}\right)_{2} \mathrm{SO}_{4}$ at $\Delta T 1$, values similar to those of Archer (1992) were obtained when we employed the Pitzer models (Pitzer and Mayorga, 1973; Clegg et al., 1996). This indicates the validity of the Pitzer model for the calculation of $S$. A similar value was obtained based on the work of Young and Warren (1992). The ideal solution approximation for $\left(\mathrm{NH}_{4}\right)_{2} \mathrm{SO}_{4}$ gave the lowest $S$. This indicates the inappropriateness of the use of this approximation for $\left(\mathrm{NH}_{4}\right)_{2} \mathrm{SO}_{4}$. Parameterizations by Tang and Munkelwitz (1994) and Kreidenweis et al. (2005) estimated the highest values of $S$. These values are significantly higher than those of Archer (1992). In the case of $\Delta T 2$, the trend is similar to $\Delta T 1$. For $\mathrm{NaCl}$ particles, $a_{w}$ given by Tang (1996) gave the lowest $S$, and the Pitzer models (Pitzer and Mayorga, 1973; Archer, 1992) gave the highest $S$. In the case of $\left(\mathrm{NH}_{4}\right)_{2} \mathrm{SO}_{4}$, the ideal solution approximation gave the lowest values, and the Pitzer models (Pitzer and Mayorga, 1973; Clegg et al., 1996) and that of Young and Warren (1992) gave similar values. These trends are similar to that of Rose et al. (2008). However, unlike the case of $\Delta T 1$, a relatively large difference $(0.005 \%$ in absolute terms) between Clegg et al. (1996) and Archer (1992) was observed at $\Delta T 2$. So far, we have been unable to determine what caused this difference.

To summarize the above discussion, the Pitzer models (Pitzer and Mayorga, 1973; Archer, 1992; Clegg, 1996) are valid to estimate critical $S$ values within an uncertainty of $2 \%$ (relative). The ideal solution approximation gives lower values of the critical $S$, and the parameterizations by Tang and Munkelwitz (1994) and Kreidenweis et al. (2005) yield higher values for $\left(\mathrm{NH}_{4}\right)_{2} \mathrm{SO}_{4}$. These parameterizations are based on the data of hygroscopic growth up to $\mathrm{RH}=95 \%$. The concentration of the $\left(\mathrm{NH}_{4}\right)_{2} \mathrm{SO}_{4}$ solution at this RH is about $m=1.5 \mathrm{~mol} \mathrm{Kg}^{-1}$. Figure 6 shows the $\phi$ of $\left(\mathrm{NH}_{4}\right)_{2} \mathrm{SO}_{4}$ given by Clegg et al. (1996). In the case of $m<1 \mathrm{~mol} \mathrm{Kg}^{-1}, \phi$ decreases with an increase in $m$ because

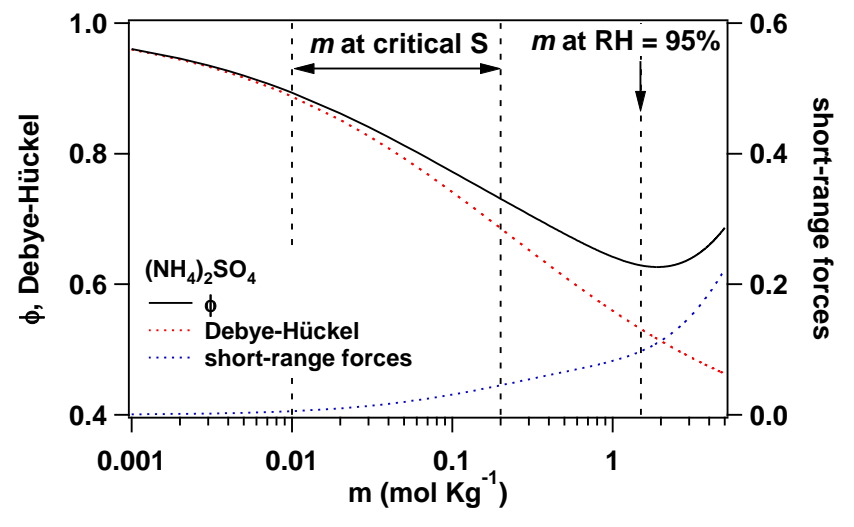

Fig. 6. $\phi$ and related parameters for an aqueous solution of $\left(\mathrm{NH}_{4}\right)_{2} \mathrm{SO}_{4}$ calculated based on the work of Clegg et al. (1996). "Debye-Hückel term" is the first two terms in Eq. (B2), and "shortrange forces"corresponds to the third and fourth terms in the same equation.

of the Debye-Hückel effect. However, $\phi$ increases with the increase in $m$ for $m>2 \mathrm{~mol} \mathrm{Kg}^{-1}$ due to short-range forces. This shows that the thermodynamic properties of $\left(\mathrm{NH}_{4}\right)_{2} \mathrm{SO}_{4}$ solutions change at around $1.5 \mathrm{~mol} \mathrm{Kg}^{-1}$. Values of $m$ at critical $S$ values of $\left(\mathrm{NH}_{4}\right)_{2} \mathrm{SO}_{4}$ particles were calculated to be $0.01 \sim 0.2 \mathrm{~mol} \mathrm{Kg}^{-1}(S=0.1 \sim 1 \%)$, and thus the parameterizations based on a concentration range of $m>1.5 \mathrm{~mol} \mathrm{Kg}^{-1}$ are not always appropriate to calculate critical $S$ values because they overestimate the magnitude of the non-ideality of the solution, which corresponds to an overestimation of critical $S$.

\section{Summary and conclusion}

In this study, we measured $\mathrm{CCN} / \mathrm{CN}$ ratios and $m_{p}$ of sizeselected $\left(\mathrm{NH}_{4}\right)_{2} \mathrm{SO}_{4}$ and $\mathrm{NaCl}$ particles. $\mathrm{CCN} / \mathrm{CN}$ ratios were measured using a CCNC and a CPC, and $m_{p}$ was measured using an APM and a CPC. The CCNC was operated 
under two conditions $(\Delta T 1$ and $\Delta T 2)$. The $d_{c \_m e}$ values of $\left(\mathrm{NH}_{4}\right)_{2} \mathrm{SO}_{4}$ were $115.2 \mathrm{~nm}(\Delta T 1)$ and $75.3 \mathrm{~nm}(\Delta T 2)$. In the case of $\mathrm{NaCl}$, these values were $94.7 \mathrm{~nm}(\Delta T 1)$ and $63.2 \mathrm{~nm}(\Delta T 2) . d_{v e}$ calculated from $m_{p}$ and $\rho_{m}$ were smaller than $d_{m e}$ by about 1 and $5 \%$ for $\left(\mathrm{NH}_{4}\right)_{2} \mathrm{SO}_{4}$ and $\mathrm{NaCl}$, respectively. Thus, it is a good approximation to treat $\left(\mathrm{NH}_{4}\right)_{2} \mathrm{SO}_{4}$ particles as spherical particles.

$d_{c_{-} v e}$ values were estimated from $d_{c_{-} m e}$ and measured $\rho_{\mathrm{eff}}$, and they were used as input parameters for Köhler theory calculations. Then, $S$ values inside the CCNC were estimated using several thermodynamics models. In these calculations, we regarded that the Pitzer model for $\mathrm{NaCl}$ (Archer, 1992) was the most reliable, as it was in excellent agreement with the experimental data, including the concentration range that is important for $\mathrm{CCN}$ activation. The values obtained for $\left(\mathrm{NH}_{4}\right)_{2} \mathrm{SO}_{4}$ and $\mathrm{NaCl}$ agreed to within a difference of $2 \%$ (relative) when the Pitzer model was employed for the calculation. This result indicates that application of the Pitzer model for calibrating a CCNC gives the most probable values of $S$.

\section{Appendix A}

\section{List of parameters}

See Table A1.

\section{Appendix B}

\section{Thermodynamics models for $a_{w}$ of inorganic salt}

In this section, we review the thermodynamics models of $\left(\mathrm{NH}_{4}\right)_{2} \mathrm{SO}_{4}$ and $\mathrm{NaCl}$ employed in this study to estimate $S$ in the CCNC.

\section{B1 Ideal solution approximation}

The simplest model is the ideal solution approximation $(\phi=1)$. Although it may be too simple (e.g., Young and Warren, 1992), this approximation has been used to calibrate CCNCs in many studies (e.g., Raymond and Pandis, 2002; Roberts and Nenes, 2005). The manufacture of CCNC also relies on this model (Shilling et al., 2007). Thus, it is important to compare this model with more sophisticated models.

\section{B2 Pitzer model}

Pitzer developed a semi-empirical model to calculate $\phi$ (Pitzer, 1973). Using the original Pitzer model, $\phi$ of a single electrolyte can be calculated by the following equation (see Appendix A for the notation of parameters):

$$
\begin{aligned}
\varphi & =1-\left|z_{m} z_{x}\right| A_{\phi} \frac{\sqrt{I}}{1+1.2 \sqrt{I}}+m \frac{2 v_{m} v_{x}}{v}\left(\beta_{M X}^{(0)}\right. \\
& \left.+\beta_{M X}^{(1)} \exp (-\alpha \sqrt{I})\right)+m^{2} \frac{\left(2 v_{m} v_{x}\right)^{3 / 2}}{v} C_{M X}^{\phi} .
\end{aligned}
$$

The first two terms are derived from Debye-Hückel theory, and the third and fourth terms express short-range interactions (e.g., ion-molecular interactions). $A_{\phi}$ can be calculated as a function of temperature using the polynomial equation given by Clegg et al. (1994), which is based on the study of Archer and Wang (1990). Pitzer and Mayorga (1973) determined three parameters $\left(\beta_{M X}^{(0)}, \beta_{M X}^{(1)}\right.$ and $\left.C_{M X}^{\phi}\right)$ for $\mathrm{NaCl}$ and $\left(\mathrm{NH}_{4}\right)_{2} \mathrm{SO}_{4}$ using experimental data reviewed by Electrolyte Solutions (Robinson and Stokes, 2002). The model has been used for the calibration of CCNCs (e.g., Mochida et al., 2006) and compared with other models by Rose et al. (2008).

Archer (1991) modified Eq. (B1) as follows:

$$
\begin{aligned}
\varphi= & 1-\left|z_{m} z_{x}\right| A_{\phi} \frac{\sqrt{I}}{1+1.2 \sqrt{I}}+m \frac{2 v_{m} v_{x}}{v} \\
& \left(\beta_{M X}^{(0)}+\beta_{M X}^{(1)} \exp (-\alpha \sqrt{I})\right)+m^{2} \frac{4 v_{m}^{2} v_{x}}{v} \\
& \left(C_{M X}^{(0)}+C_{M X}^{(1)} \exp \left(-\alpha_{2} \sqrt{I}\right)\right)
\end{aligned}
$$

Archer (1992) gave the parameters of the above equation for $\mathrm{NaCl}$ as a function of temperature and pressure. Experimental data used by Archer (1992) cover the concentration range that is important for the calculation of critical $S$ (on the order of $10^{-1} \sim 10^{-2} \mathrm{~m}$ ). Thus, we regard this model as giving the most reliable value (Clegg, 2007). Note that the correction given by Clegg et al. (1994) should be employed for the use of the work of Archer (1992). Clegg et al. (1996) obtained parameters for Eq. (B2) for $\left(\mathrm{NH}_{4}\right)_{2} \mathrm{SO}_{4}$, and their results have been used in some CCN studies (e.g., Kumar et al., 2003), and it has been compared extensively with other models by Kreidenweis et al. (2005).

\section{B3 van't Hoff factor}

Another method to express the non-ideal behavior of inorganic electrolyte solutions is the use of $i$. One of the most widely used expressions for $i$ was derived by Young and Warren (1992):

$i=1.9242-0.1844 \ln (\mathrm{m})-0.007931(\ln (\mathrm{m}))^{2}$

This equation is applicable only to $\left(\mathrm{NH}_{4}\right)_{2} \mathrm{SO}_{4}$. The value from this model has been used in some studies (e.g., Svenningsson et al., 2006; Frank et al., 2007) and compared with other models by Rose et al. (2008).

\section{B4 Polynomial equation}

Tang and Munkelwitz (1994) and Tang (1996) measured hygroscopic growth of $\left(\mathrm{NH}_{4}\right)_{2} \mathrm{SO}_{4}$ and $\mathrm{NaCl}$ using the 
Table A1. List of parameters.

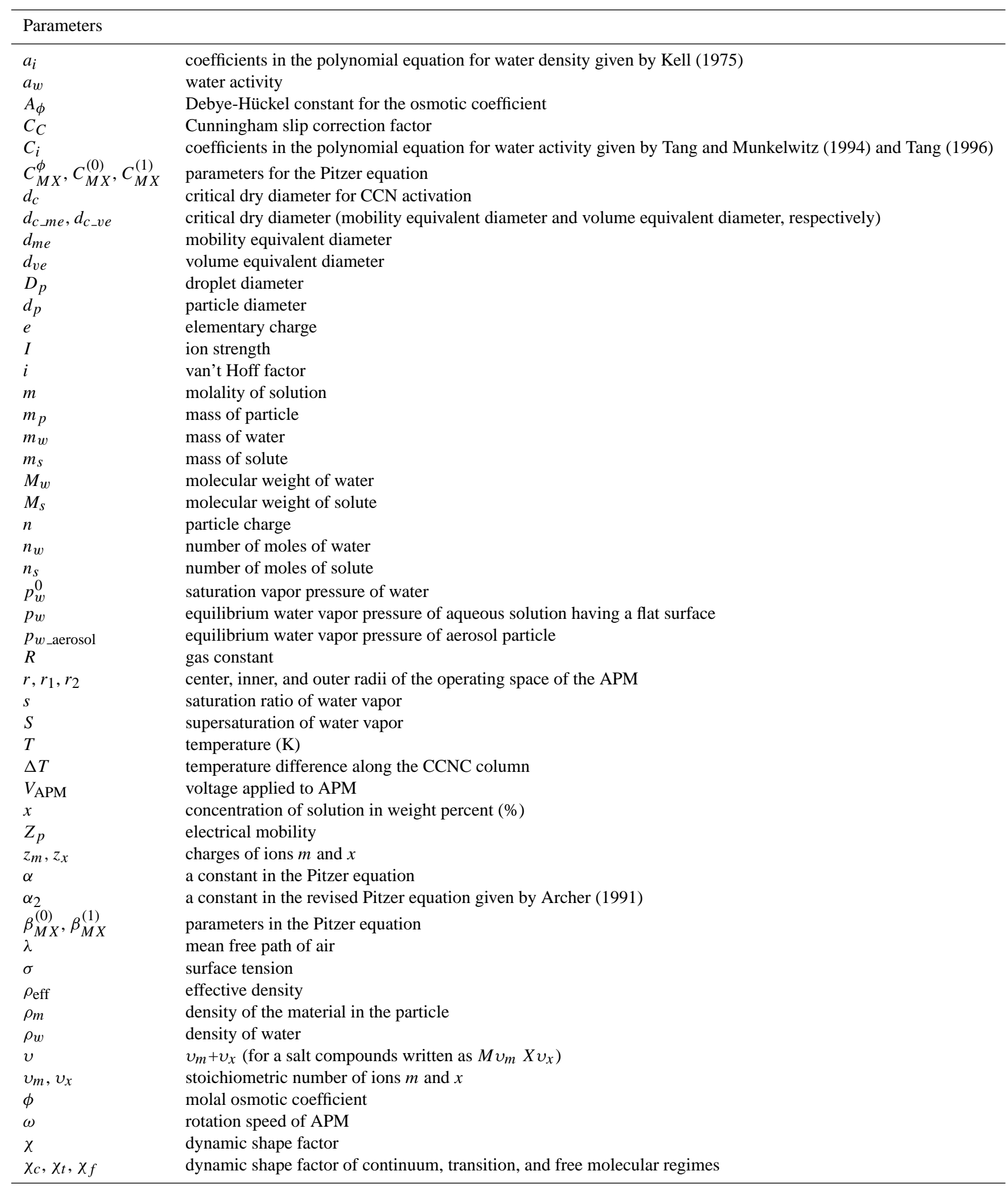


electrodynamic balance (EDB) technique. They summarized the experimental results with the following polynomial function:

$a_{w}=1.0+\sum C_{i} x^{i}$

where $C_{i}$ are constants, and $x$ is the concentration of the solution in weight $\%$. This model has also been used to calibrate a CCNC (e.g., Snider et al., 2006) and compared with other models by Kreidenweis et al. (2005) and Rose et al. (2008).

Kreidenweis et al. (2005) fitted the growth factors (GFs) of $\left(\mathrm{NH}_{4}\right)_{2} \mathrm{SO}_{4}$ and $\mathrm{NaCl}$ particles measured by a hygroscopic tandem DMA with the following equation:

$\mathrm{GF}=\frac{d_{m e \_ \text {wet }}}{d_{m e \_ \text {dry }}}=\left(1+\left(a+b a_{w}+c a_{w}^{2}\right) \frac{a_{w}}{1-a_{w}}\right)^{1 / 3}$

where $a, b$, and $c$ are constants, and $d_{m e \_ \text {wet }}$ and $d_{m e \_d r y}$ denote the wet and dry particle diameters, respectively. This model has also been used for some CCN studies (e.g., Mochida et al., 2006; Rose et al., 2008).

\section{Appendix C}

\section{$\rho_{w}$ and $\sigma$}

Here we summarize values of $\rho_{w}$ and $\sigma$ employed for the calculation of critical $S . \rho_{w}$ depends both on temperature (Kell, 1975) and the concentration of solute (Tang and Munkelwitz, 1994; Tang, 1996). However, the density of the solution is available only at $25^{\circ} \mathrm{C}$, and the influence of the solute on the density of solution near the critical $D_{p}$ is estimated to be small. Thus, we employed the temperature-dependent water density given by Kell (1975), which is written as follows:

$\rho_{w}=\frac{\sum_{i=0}^{5} a_{i} T^{i}}{1+a_{-1} T}$

where $a_{i}$ are constants.

$\sigma$ also depends on temperature and chemical composition (Seinfeld and Pandis, 2006). We employed the following set of equations to calculate $\sigma$ :

$\sigma_{\left(\mathrm{NH}_{4}\right) 2 \mathrm{SO}_{4}}=\sigma_{\text {-water }}(T)+2.17 \times 10^{-3} \mathrm{~m}_{\left(\mathrm{NH}_{4}\right) 2 \mathrm{SO}_{4}}$

$\sigma_{\mathrm{NaCl}}=\sigma_{- \text {water }}(T)+1.62 \times 10^{-3} \mathrm{~m}_{\mathrm{NaCl}}$

where

$$
\begin{aligned}
\sigma_{\text {water }}(T) & =235.8 \times 10^{-3}\left(\frac{T_{c}-T}{T_{c}}\right)^{1.256} \\
& \left(1-0.625\left(\frac{T_{c}-T}{T_{c}}\right)\right)\left(T_{c}=647.15 \mathrm{~K}\right)
\end{aligned}
$$

Equations (C2) and (C3) are taken from Seinfeld and Pandis (2006) and Eq. (C4) was given by Vargaftik et al. (1983).
Acknowledgements. This work was supported by the Ministry of Education, Culture, Sports, Science, and Technology (MEXT) and the global environment research fund of the Japanese Ministry of the Environment (B-083). M. Kuwata thanks to the Japan Society for the Promotion of Science (JSPS) for a JSPS Research Fellowship for Young Scientists.

Edited by: G. Roberts

\section{References}

Allen, M. D. and Raabe, O. G.: Slip correction measurements of spherical solid aerosol particles in an improved Millikan apparatus, Aerosol Sci. Tech., 4, 269-286, 1985.

Archer, D. G. and Wang, P.: The dielectric constant of water and Debye-Hückel limiting law slopes, J. Phys. Chem. Ref. Data, 19, 371-411, 1990.

Archer, D. G.: Thermodynamic properties of the $\mathrm{NaBr}+\mathrm{H}_{2} \mathrm{O}$ system, J. Phys. Chem. Ref. Data, 20, 509-535, 1991.

Archer, D. G.: Thermodynamic properties of the $\mathrm{NaCl}+\mathrm{H}_{2} \mathrm{O}$ system II. Thermodynamic properties of $\mathrm{NaCl}(\mathrm{aq}), \mathrm{NaCl}_{2} \mathrm{H}_{2} \mathrm{O}$ (cr), and phase equilibria, J. Phys. Chem. Ref. Data, 21, 793-821, 1992.

Biskos, G., Paulsen, D., Russell, L. M., Buseck, P. R., and Martin, S. T.: Prompt deliquescence and efflorescence of aerosol nanoparticles, Atmos. Chem. Phys., 6, 4633-4642, 2006a, http://www.atmos-chem-phys.net/6/4633/2006/.

Biskos, G., Russel, L. M., Buseck, P. R., and Martin, S. T.: Nanosize effect on the hygroscopic growth factor of aerosol particles, Geophys. Res. Lett., 33, L07801, doi:10.1029/2005GL025199, 2006b.

Clegg, S. L., Rard, J. A., and Pitzer, K. S.: Thermodynamic properties of $0-6 \mathrm{~mol} \mathrm{Kg}^{-1}$ aqueous sulfuric acid from 273.15 to 328.15 K, J. Chem. Soc. Faraday T., 90(13), 1875-1894, 1994.

Clegg, S. L., Milioto, S., and Palmer, D. A.: Osmotic and activity coefficients of aqueous $\left(\mathrm{NH}_{4}\right)_{2} \mathrm{SO}_{4}$ as a function of temperature, and aqueous $\left(\mathrm{NH}_{4}\right)_{2} \mathrm{SO}_{4}-\mathrm{H}_{2} \mathrm{SO}_{4}$ mixtures at $298.15 \mathrm{~K}$ and 323.15 K, J. Chem. Eng. Data, 41, 455-467, 1996.

Clegg, S. L.: Interactive comment on "Calibration and measurement uncertainties of a continuous-flow cloud condensation nuclei counter (DMT-CCNC): CCN activation of ammonium sulfate and sodium chloride aerosol particles in theory and experiments" by D. Rose et al., Atmos. Chem. Phys. Discuss., 7, S4180-S4183, 2007.

Dahneke, B. E.: Slip correction factors for nonspherical bodies-III the form of the general law, J. Aerosol Sci., 4, 163-170, 1973.

DeCarlo, P. F., Slowik, J. G., Worsnop, D. R., Davidovits, P., and Jimenez, J. L.: Particle morphology and density characterization by combining mobility and aerodynamic diameter measurements. Part 1: Theory, Aerosol Sci. Tech., 38, 1185-1205, 2004.

Dick, W. D., Ziemann, P. J., Huang, Po-Fu., and McMurry, P. H.: Optical shape fraction measurements of submicrometre laboratory and atmospheric aerosols, Meas. Sci. Technol., 9, 183-196, 1998.

Ehara, K., Hagwood, C., and Coakley, K. J.: Novel method to classify aerosol particles according to their mass-to-charge ratioaerosol particle mass analyzer, J. Aerosol Sci., 27(2), 217-234, 1996. 
Frank, G. P., Dusek, U., and Andreae, M. O.: Technical Note: Characterization of a static thermal-gradient $\mathrm{CCN}$ counter, Atmos. Chem. Phys., 7, 3071-3080, 2007, http://www.atmos-chem-phys.net/7/3071/2007/.

Hinds, W. C.: Aerosol Technology, John Wiley and Sons, Inc., 1999.

Kasper, G.: Dynamics and measurements of Smokes. I size characterization of nonspherical particles, Aerosol Sci. Tech., 1, 187199, 1982.

Kell, G. S.: Precise representation of volume properties of water at one atmosphere, J. Chem. Eng. Data, 12(1), 66-69, 1967.

Kelly, W. P. and McMurry, P. H.: Measurements of particle density by inertial classification of differential mobility analyzergenerated monodisperse aerosols, Aerosol Sci. Tech., 17, 199212, 1992.

Kreidenweis, S. M., Koehler, K., DeMott, P. J., Prenni, A. J., Carrico, C., and Ervens, B.: Water activity and activation diameters from hygroscopicity data - Part I: Theory and application to inorganic salts, Atmos. Chem. Phys., 5, 1357-1370, 2005, http://www.atmos-chem-phys.net/5/1357/2005/.

Pradeep Kumar, P., Broekhuizen, K., and Abbatt, J. P. D.: Organic acids as cloud condensation nuclei: Laboratory studies of highly soluble and insoluble species, Atmos. Chem. Phys., 3, 509-520, 2003, http://www.atmos-chem-phys.net/3/509/2003/.

Lohmann, U. and Feichter, J.: Global indirect aerosol effects: a review, Atmos. Chem. Phys., 5, 715-737, 2005, http://www.atmos-chem-phys.net/5/715/2005/.

McMurry, P. H.: A review of atmospheric aerosol measurements, Atmos. Environ., 34, 1959-1999, 2000.

Mikhailov, E., Vlasenko, S., Niessner, R., and Pöschl, U.: Interaction of aerosol particles composed of protein and saltswith water vapor: hygroscopic growth and microstructural rearrangement, Atmos. Chem. Phys., 4, 323-350, 2004,

http://www.atmos-chem-phys.net/4/323/2004/.

Mochida, M., Kuwata, M., Miyakawa, T., Takegawa, N., Kawamura, K., and Kondo, Y.: Relationship between hygroscopicity and cloud condensation nuclei activity for urban aerosols in Tokyo, J. Geophys. Res., 111, D23204, doi:10.1029/2005JD006980, 2006.

Nenes, A., Chuang, P. Y., Flagan, R. C., and Seinfeld, J. H.: A theoretical analysis of cloud condensation nucleus $(\mathrm{CCN})$ instruments, J. Geophys. Res., 106(D4), 3449-3474, 2001.

Otto, P., Georgii, H-W., and Bingemer H.: A new three-stage continuous flow CCN-counter, Atmos. Res., 61, 299-310, 2002.

Park, K., Kittelson, D. B., and McMurry, P. H.: Structural properties of diesel exhaust particles measured by transmission electron microscope (TEM): relationships to particle mass and mobility, Aerosol Sci. Tech., 38, 881-889, 2004.

Pitzer, K. S.: Thermodynamics of Electrolytes. I. Theoretical basis and general equations, J. Phys. Chem., 77(2), 268-277, 1973.

Pitzer, K. S. and Mayorga, G.: Thermodynamics of electrolytes. II. Activity and osmotic coefficients for strong electrolytes with one or both ions univalent, J. Phys. Chem., 77(19), 2300-2308, 1973.

Pruppacher, H. R., and Klett, J. D.: Microphysics of Clouds and Precipitation, Kluwer Academic Publishers, 1997.

Raymond, T. M. and Pandis, S. N.: Cloud activation of single-component organic aerosol particles, J. Geophys. Res., 107(D24), 4787, doi:10.1029/2002JD002159, 2002.
Rissman, T. A., Varutbangkul, V., Surratt, J. D., Topping, D. O., McFiggans, G., Flagan, R. C., and Seinfeld, J. H.: Cloud condensation nucleus $(\mathrm{CCN})$ behavior of organic aerosol particles generated by atomization of water and methanol solutions, Atmos. Chem. Phys., 7, 2949-2971, 2007,

http://www.atmos-chem-phys.net/7/2949/2007/.

Roberts, G. C. and Nenes, A.: A continuous-flow streamwise thermal-gradient $\mathrm{CCN}$ chamber for atmospheric measurements, Aerosol Sci. Tech., 39, 206-221, 2005.

Robinson, R. A. and Stokes, R. H.: Electrolyte Solutions, second revised edition, Dover Publications, Inc., 2002.

Rose, D., Gunthe, S. S., Mikhailov, E., Frank, G. P., Dusek, U., Andreae, M. O., and Pöschl, U.: Calibration and measurement uncertainties of a continuous-flow cloud condensation nuclei counter (DMT-CCNC): CCN activation of ammonium sulfate and sodium chloride aerosol particles in theory and experiment, Atmos. Chem. Phys., 8, 1153-1179, 2008, http://www.atmos-chem-phys.net/8/1153/2008/.

Seinfeld, J. H. and Pandis, S. N.: Atmospheric Chemistry and Physics, John Wiley and Sons, Inc., New York, 2006.

Shilling, J. E., King, M. E., Mochida, M., Worsnop, D. R., and Martin, S. T.: Mass spectral evidence that small changes in composition caused by oxidative aging processes alter aerosol CCN properties, J. Phys. Chem. A, 111, 3358-3368, 2007.

Snider, J. R., Petters, M. D., Wechsler, P., and Liu, P. S.: Supersaturation in the Wyoming CCN instrument, J. Atmos. Ocean. Technol., 23, 1323-1339, 2006.

Stratmann, F., Kiselev, A., Wendisch, M., Heintzenberg, J., Charlson, R. J., Diehl, K., Wex, H., and Schmidt, S.: Laboratory studies and numerical simulations of cloud droplet formation under realistic supersaturation conditions, J. Atmos. Ocean. Tech., 21, 876-887, 2004.

Svenningsson, B., Rissler, J., Swietlicki, E., Mircea, M., Bilde, M., Facchini, M. C., Decesari, S., Fuzzi, S., Zhou, J., Mønster, J., and Rosenørn, T.: Hygroscopic growth and critical supersaturations for mixed aerosol particles of inorganic and organic compounds of atmospheric relevance, Atmos. Chem. Phys., 6, 1937-1952, 2006, http://www.atmos-chem-phys.net/6/1937/2006/.

Tang, I. N. and Munkelwitz, H. R.: Water activities, densities, and refractive indices, of aqueous sulfates and sodium nitrate droplets of atmospheric importance, J. Geophys. Res., 99(D9), 18801$18808,1994$.

Tang, I. N.: Chemical and size effects of hygroscopic aerosols on light scattering coefficients, J. Geophys. Res., 101(D14), 1924519250, 1996.

Twomey, S.: Pollution and the planetary albedo, Atmos. Environ., 8, 1251-1256, 1974.

VanReken, T. M., Ng, N. L., Flagan, R. C., and Seinfeld, J. H.: Cloud condensation nuclei activation properties of biogenic secondary organic aerosol, J. Geophys. Res., 110, D07206, doi:10.1029/2004JD005465, 2005.

Vargaftik, N. B., Volkov, B. N., and Voljak, L. D.: International tables of the surface tension of water, J. Chem. Eng. Data, 12(3), 817-820, 1983.

Young, K. C. and Warren, A. J.: A reexamination of the derivation of the equilibrium supersaturation curve for soluble particles, J. Atmos. Sci., 49(13), 1138-1143, 1992. 
Zelenyuk, A., Cai, Y., and Imre D.: From agglomerates of spheres to irregularly shaped particles: determination of dynamic shape factors from measurements of mobility and vacuum aerodynamic diameter, Aerosol Sci. Technol., 40, 190-217, 2006a.
Zelenyuk, A., Imre, D., and Cuadra-Rodriguez, A. L.: Evaporation of water from particles in the aerodynamic lens inlet: an experimental study, Anal. Chem., 78, 6942-6947, 2006 b. 